Volume 5 Nomor. 1, April 2020

P -ISSN : 2541-1179, E-ISSN : 2581-1711

Ojs :http://journal.uin-alauddin.ac.id/index.php/instek/index

Email : instek@uin-alauddin.ac.id

\title{
OTOMATISASI PEMUSATAN JARINGAN IPV4 dan IPV6 MENGGUNAKAN RIVERBED MODELER
}

\section{MUHAMMAD IMAM GHOZALI}

\author{
Fakultas Teknik \\ Universitas Muria Kudus \\ E-mail : \\ imam.ghozali@umk.ac.id
}

\begin{abstract}
ABSTRAK
Simulasi jaringan adalah teknik untuk menguji operasi teknologi atau protokol sebelum penyebaran aktualnya, atau bahkan selama penyebaran. Konsep-konsep ini terkait konsistensi Kualiatas Layanan dua protokol IPv4 dan IPv6 dalam jaringan skala besar seperti internet. Tidak ada yang dapat menyangkal bahwa sebagian besar Penyedia Layanan Internet (ISP) hanya menyediakan jaringan akses berbasis IPv4, namun, klien dapat menggunakan IPv6 secara lokal. Beberapa mekanisme transisi dan teknik penerjemahan alamat dapat digunakan untuk mengakomodir interkoneksi dua protokol yang berbeda. Dalam makalah ini, kami mengusulkan pendekatan baru untuk mengotomatisasi simulasi mekanisme transisi IPv6 dan IPv4 dalam jaringan skala besar. Pendekatan yang diusulkan dengan simulator Riverbed Modeler dan dapat dimodifikasi untuk memasukkan simulator jaringan lainnya. Hasil evaluasi pendekatan menunjukkan bahwa durasi pengaturan jaringan komputer dengan 100 node IPv6 yang saling berhubungan melalui jaringan IPv4 tidak melebihi total 30 detik.
\end{abstract}

Kata Kunci : simulasi,otomatisasi,ipv4,ipv6, riverbed modeler, jaringan komputer

\section{PENDAHULUAN}

Perkembangan peralatan Teknologi Informasi sekarang ini semakin berkembang signifikan, peran internet sangat penting hampir di setiap aspek kehidupan manusia. Dengan Teknologi Informasi memungkinkan manusia untuk memvisualisasikan, menghitung, memprediksi, dan meningkatkan kinerja sistem yang akan di implementasikan. Dalam rangka mewujudkan efisiensi waktu dan meminimalisir kesalahan dalam tahap implementasi, rekayasa jaringan komputer 


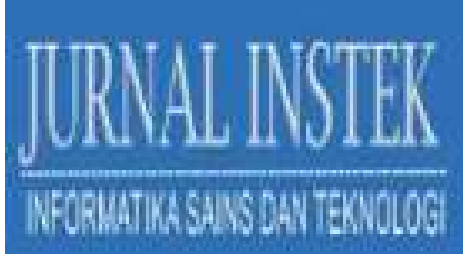

Volume 5 Nomor. 1, April 2020

P -ISSN : 2541-1179, E-ISSN : 2581-1711

Ojs :http://journal.uin-alauddin.ac.id/index.php/instek/index

Email : instek@uin-alauddin.ac.id

perlu dilakukan tahap simulasi terlebih dahulu. Simulasi adalah proses yang diperlukan untuk meniru tingkah laku sistem yang sesungguhnya. Dalam praktek antara modeling dan simulasi berhubungan sangat erat. Simulasi juga dapat didefinisikan sebagai pengimitasian proses dari kejadian ril atau kenyataannya. Dimana simulasi bertujuan untuk menghadirkan sistem riil dalam bentuk maya melalui penggunaan tiruan dari komponen-komponen dan strukturnya. Simulasi jaringan komputer merupkan salah satu elemen utama dari tiga fase pengembangan jaringan komputer (sebelum, saat dan setelah). Ini memungkinkan untuk melihat beberapa teknis pilihan dan juga dampaknya terhadap kinerja seluruh sistem.

Perangkat lunak simulasi juga dapat digunakan untuk memprediksi kebutuhan sistem topologi jaringan yang berbeda. Untuk itu, perlu memodelkan sistem jaringan komputer sesuai dengan yang akan di implementasikan di lapangan dengan benar agar memiliki hasil yang andal.

Dalam Simulasi jaringan komputer yang kompleks, dapat mempertimbangkan beberapa aspek antara lain, Banyaknya jumlah peralatan yang dipakai, perbedaan teknologi yang dapat digunakan, dan jumlah parameter yang dapat mendukung peralatan. Sebagai contoh jaringan internet kampus. Selain itu, ketrampilan spesifik sumber daya manusia yang dibutuhkan keterampilan tertentu, antara lain:

1. Administrator harus mengatur peralatan, menghubungkan dan mengembangkan dua rencana pengalamatan IPv4 dan IPv6.

2. Administrator harus menguasai langkah-langkah untuk menggunakan teknik transisi IPv4-IPv6 di software simulasi Riverbed modeler.

3. Administrator harus mengulangi skenario yang sama beberapa kali dengan metode transisi yang berbeda.

4. Administrator harus berhati-hati dengan parameter simulasi agar tidak mengganggu keandalan hasil simulasi.

Simulasi jaringan komputer skala besar dari dua protokol IPv4 dan IPv6 relatif rumit karena memerlukan keterampilan pengalamatan, perutean, dan penerapan praktik untuk masing-masing protokol ini. Beberapa faktor menyulitkan simulasi, yaitu 
ukuran jaringan akhir dan jaringan perantara, protokol routing IPv4 dan IPv6 yang digunakan, dan mekanisme tunneling yang harus diimplementasikan. Namun demikian alamat IP dapat dikatakan lebih penting karena pengguna tidak akan mampu merancang dan membangun sistem dan keamanan jaringan yang mumpuni seperti Local Area Network (LAN), Game Center Online, Hostpot Area, Wide Area Network (WAN), Metropolitan Area Network (MAN), Intranet, Internetwork, Sistem Informasi Online, Ticketting, Content, dan seterusnya tanpa menguasai Alamat IP.

Internet didefinisikan sebagai seperangkat peralatan yang saling berhubungan dengan maksud menyampaikan informasi dari sumber ke tujuan. Protokol jaringan komputer yang digunakan dalam jaringan ini adalah IPv4 yang terbatas memberikan rentang alamat tambahan, keamanan dan, Kualitas Layanan (QoS). QoS juga menyediakan kualitas dari jaringan komputer walaupun dengan penggunaan teknologi yang berbeda[3]. Sehingga muncul protokol IPv6 yang baru sebagai solusi mengatasi keterbatasan IPv4 tetapi tidak banyak digunakan oleh sebagian besar Penyedia Layanan Internet (ISP). Akibatnya, jaringan perantara operator terkadang hanya menyediakan IPv4 saja, namun klien menggunakan IPv6. Gambar 1 mengilustrasikan data pertukaran prefiks IPv4 internet service di indonesia dalam sistem otonom sekarang ini.

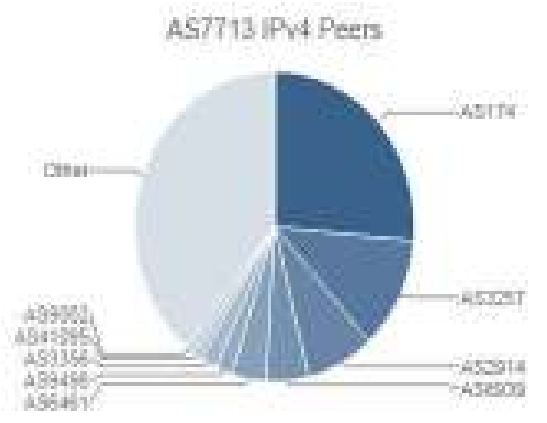

\begin{tabular}{|c|c|}
\hline ASK & Nanta \\
\hline dQ: & Caovetesomincotoses \\
\hline 389:2]. & erticonentuatoula \\
\hline $6822+4$ & NIT Arivica inc. \\
\hline Astive: & 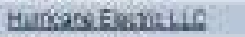 \\
\hline ASTiaft & zave Banowath \\
\hline agrals & Ehodisoung \\
\hline A63ase: & has 3 Batart be \\
\hline derions & IETHLIR: \\
\hline $190 \times 10$ & BEINifuter \\
\hline
\end{tabular}

Gambar 1. Jumlah prefix IPv4 vs IPv6 yang dihasilkan dari sistem otonom AS6713.

Gambar diatas menunjukkan prefiks Protokol IPv6 yang digunakan dalam sistem otonom saat ini masih sangat sedikit. Sementara untuk menghubungkan dua 
Volume 5 Nomor. 1, April 2020

P -ISSN : 2541-1179, E-ISSN : 2581-1711

Ojs :http://journal.uin-alauddin.ac.id/index.php/instek/index

Email : instek@uin-alauddin.ac.id

situs, Protokol IPv6 melintasi infrastruktur Protokol IPv4. Sepenuhnya, dua metode dapat digunakan, baik mengenkapsulasi paket IPv6 ke IPv4 lain dan mengirim melalui IPv4 (Tunneling) atau menerjemahkan alamat IPv6 ke alamat IPv4 di antarmuka transmisi dan sebaliknya, di antarmuka penerima.

\section{METODE PENELITIAN}

Arsitektur yang diusulkan didasarkan pada tiga lapisan logis: bidang data, bidang kontrol, dan bidang manajemen. Gambar 2 mengilustrasikan semua bidang arsitektur jaringan.

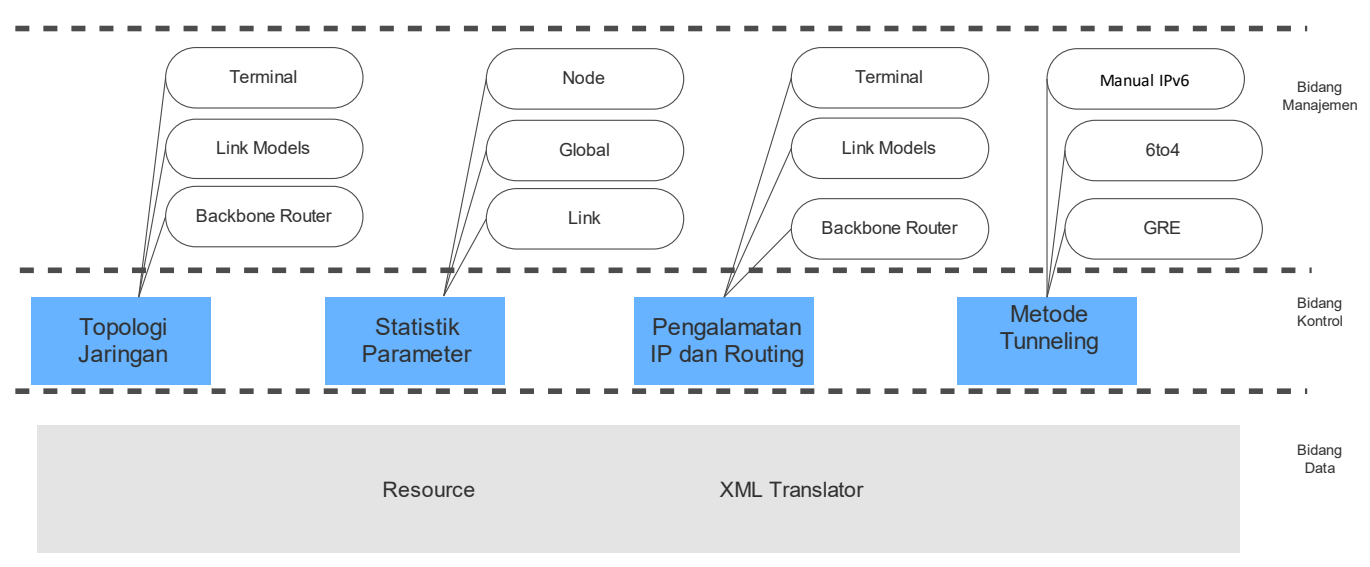

Gambar 2. Arsitektur solusi otomatisasi simulasi mekanisme transisi IPv4 / IPv6.

- Topologi Jaringan: Modul ini mendefinisikan topologi jaringan untuk disimulasikan, di bagian ini beberapa parameter dijelaskan dalam bidang manajemen, di antaranya menyebutkan jumlah jembatan yang membentuk jaringan perantara serta jumlah jembatan yang mewakili gerbang yang terletak di area pelanggan. Interkoneksi berbagai peralatan dari jaringan perantara dapat dilakukan sesuai dengan profil yang telah ditentukan secara default (benar-benar menyatu, sebagian menyatu atau dalam cincin) atau sesuai dengan pilihan yang dipersonalisasi oleh pengguna. Interkoneksi antar topologi dapat dilakukan sesuai dengan kategori (10/100/1000baseT, E1, T1, DS3, OC3, dll.). Modul ini juga mendefinisikan klien dan server yang digunakan dalam arsitektur serta aplikasi yang disimulasikan. Parameter lain dapat diberikan melalui modul ini seperti ukuran zona jaringan dan produsen peralatan. 
Volume 5 Nomor. 1, April 2020

P -ISSN : 2541-1179, E-ISSN : 2581-1711

Ojs :http://journal.uin-alauddin.ac.id/index.php/instek/index

Email : instek@uin-alauddin.ac.id

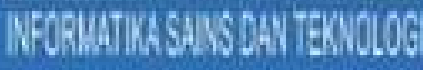

- Routing: modul ini mendefinisikan versi protokol IP yang akan diterapkan untuk setiap domain jaringan (menengah dan khir). Perhitungan subnetwork alamat jaringan diterapkan sesuai dengan rencana pengalamatan. Pengguna secara opsional dapat menentukan alamat jaringan yang akan dipotong untuk setiap domain atau segmen. Pilihan protokol routing kemudian dilakukan sesuai dengan logika yang sama. Arsitektur simulasi yang kami sampaikan mendukung protokol routing sebagai berikut: Static, RIP, OSPF, EIGRP dan IS-IS.

- Tunneling: modul ini memungkinkan untuk memilih metode tunneling untuk diterapkan antara jaringan sumber dan tujuan. Beberapa metode tunneling didukung oleh arsitektur kami, termasuk yang didukung oleh simulator Riverbed Modeler, seperti teknik manual, 6to4, GRE, dan Broker. Untuk tiga metode pertama, antarmuka terowongan dibuat, rencana pengalamatan kemudian dikembangkan dan ditetapkan sesuai dengan situs yang berkomunikasi.

- Parameter statistik: modul ini memungkinkan Anda menentukan statistik yang akan dikumpulkan. Statistik dapat bersifat global (perilaku umum seluruh jaringan), per node (kinerja perangkat tertentu dalam jaringan), atau dengan tautan (kinerja tautan, keterlambatan antrian, kesalahan bit per paket, pemanfaatan, debit).

- Resource: modul ini memungkinkan untuk membuat satu set skenario dengan memvariasikan satu atau lebih parameter. Modul ini dapat berguna jika pengguna ingin menguji skalabilitas dengan meningkatkan jumlah node atau efisiensi dari satu metode dibandingkan yang lain dengan arsitektur jaringan yang sama.

- XML: modul ini memungkinkan untuk menerjemahkan parameter sebelumnya ke dalam file XML yang kompatibel dengan simulator Riverbed Modeler.

\section{HASIL DAN PEMBAHASAN}

Pada bagian ini, evaluasi keandalan pendekatan dalam hal kecepatan pembuatan beberapa skenario yang berbeda. Evaluasi pertama adalah meningkatkan jumlah node (router tengah dan akhir) dan yang kedua adalah memvariasikan metode transisi untuk setiap skenario. Menurut penelitian kami, tidak ada solusi yang dibuat mengotomatisasi simulasi mekanisme transisi IPv6, kami membandingkan efisiensi 
Volume 5 Nomor. 1, April 2020

P -ISSN : 2541-1179, E-ISSN : 2581-1711

Ojs :http://journal.uin-alauddin.ac.id/index.php/instek/index

Email : instek@uin-alauddin.ac.id

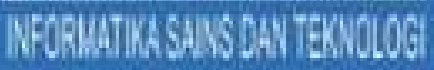

pendekatan kami dibandingkan dengan metode manual. Gambar. 3 Mengilustrasikan waktu yang dibutuhkan dalam simulasi dengan lima skenario yang jumlah node bertambah 20 .

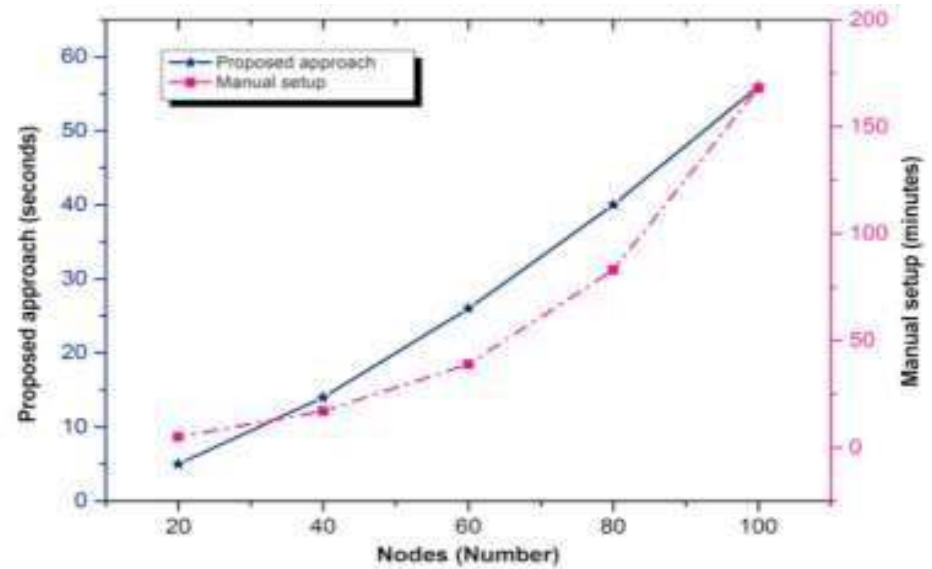

Gambar 3. Durasi simulasi dengan menambah jumlah node

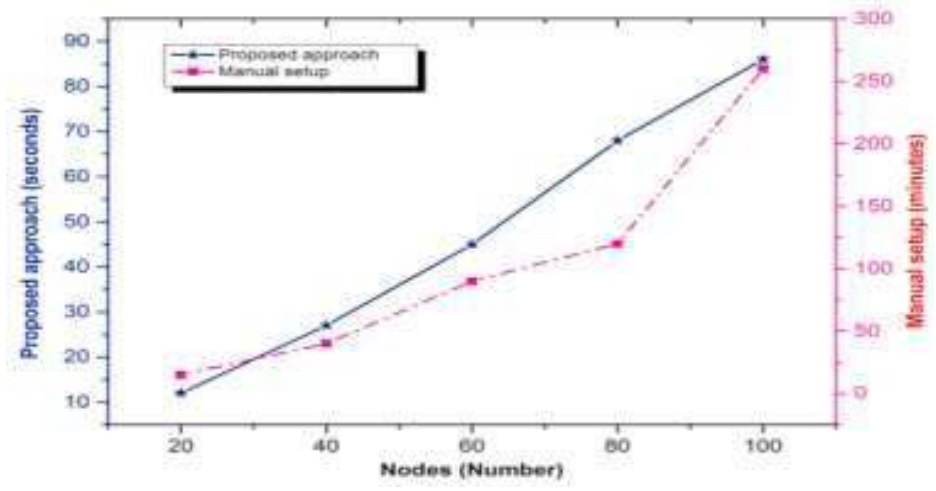

Gambar 4. Durasi simulasi dengan beragam metode tunneling.

Jelas bahwa pendekatan ini memiliki waktu implementasi yang jauh lebih pendek daripada metode manual. Untuk kasus peningkatan jumlah node menjaga mekanisme transisi yang sama IPv6 GRE. Untuk skenario yang terdiri dari 100 node, pendekatan kami membutuhkan 56 detik sementara melalui metode manual penundaan 168 menit diperlukan. Peningkatan bertahap dalam keterlambatan pendekatan kami dibenarkan terutama oleh berapa kali aplikasi mencari tag XML yang sesuai untuk suatu parameter. Mengenai hasil yang diperoleh pada Gambar. 4, kami menemukan bahwa pendekatan kami dapat menerapkan metode transisi IPv6 
Volume 5 Nomor. 1, April 2020

P -ISSN : 2541-1179, E-ISSN : 2581-1711

Ojs :http://journal.uin-alauddin.ac.id/index.php/instek/index

Email : instek@uin-alauddin.ac.id

IPv6 yang berbeda dalam skenario 100 simpul dan ini dalam waktu kurang dari 90 detik, sedangkan melalui metode manual ini membutuhkan 280 menit

\section{IV.KESIMPULAN}

Mekanisme transisi IPv6 IPv4 memungkinkan konsistensi antara Internet yang menggunakan IPv4 dengan Internet yang menggunakan IPv6. Karena itu, mengevaluasi kinerja transisi ini penting sebelum fase implementasi yang sebenarnya.. Dengan pendekatan baru untuk mengotomatisasi simulasi mekanisme transisi yang berbeda di bawah Riverbed Modeler. Hasil yang diperoleh menunjukkan efektivitas pendekatan kami dibandingkan dengan metode manual dalam hal kecepatan pengembangan proyek yang siap disimulasikan. Untuk membuat proyek 100-peralatan yang terdiri dari 4 skenario yang masing-masing memiliki mekanisme transisi spesifik, metode manual membutuhkan 280 menit sementara pendekatan kami mengurangi waktu ini menjadi 86 detik saja.

\section{DAFTAR PUSTAKA}

I. Marzuki, "Mekanisme Transisi IPv4 dan IPv6 Menggunakan Metode Automatic Tunneling Pada Jaringan Client Server Berbasis Linux," J. Teknol. Inf. Indones., vol. 3, no. 2, pp. 68-73, 2019.

R. Z. Wijaya, D. Siregar, and R. Syah, "Analisis Dan Simulasi Jaringan Menggunakan Metode Extended Access List Pada Router 2811.”

M. Ghozali, A. Murti, R. Nindyasari, W. Sugiharto, and M. Hakim, "Quality Analysis Of Service (QOS) to Measuring Quality Topology Network Computer-Based National Exam (UBNK)," pp. 1-8, 2019.

“bgp.he.net, I., . AS7713 PT Telekomunikasi Indonesia.” .

S. Wardoyo, T. Ryadi, and R. Fahrizal, "Analisis Performa File Transport Protocol Pada Perbandingan Metode IPv4 Murni, IPv6 Murni dan Tunneling 6to4 Berbasis Router Mikrotik," J. Nas. Tek. Elektro, vol. 3, no. 2, p. 106, 2014.

M. Basuki et al., "IMPLEMENTASI INTEGRASI JARINGAN IPv4 DAN JARINGAN IPv6 PADA LOCAL AREA NETWORK ( LAN ) DENGAN SISTEM TUNNELING," pp. 1-11.

R. Artondo, "Analisa dan Implementasi IPv6 Tunnel Broker Untuk Interkoneksi Antara IPv6 dan IPv4," 2011. 